\title{
Active thermographic inspection of external thermal insulation system with plastic anchors: evaluation of different thermal stimulus
}

\author{
by M. Gonçalves* ${ }^{\star \star \star *}$, N. Simões ${ }^{\star, \star *}$ and C. Serra ${ }^{\star \star \star *}$ \\ * ITeCons - Institute for Research and Technological Development for Construction, Energy, Environment and \\ Sustainability, Rua Pedro Hispano s/ n., 3030-289 Coimbra, Portugal, cserra@itecons.uc.pt \\ **ADAI - LAETA, Department of Civil Engineering, University of Coimbra, Pólo II, Rua Luís Reis Santos, 3030- \\ 788 Coimbra, Portugal
}

\begin{abstract}
The paper aims to apply infrared thermography (IRT) techniques to evaluate its capacity for the detection of plastic anchors for fixing of External Thermal Insulation Composite Systems with rendering (ETICS). The active IRT was performed in laboratory conditions based in the reflection mode. Different thermal stimuli were used, namely halogen lamps, infrared lamps and air heaters, and their results were compared. A sensitivity analysis using different types of rendering was performed. The resulting data was processed in both time and frequency domains. In this last case, phase contrast images were generated and studied.
\end{abstract}

\section{Introduction}

Buildings are responsible for $40 \%$ of energy consumption in the European Union (EU) [1]. To reduce the energy demand of buildings energy efficient measures are needed. This need is strongly supported by EU's legislation to cover the reduction of the energy consumption of buildings, such as directives on Energy Performance (EPBD) [1] and Energy Efficiency (EED) [2] of buildings. Aligned with these European directives, countries must set minimum energy performance requirements for new buildings, for the major renovation of buildings, and for the replacement or retrofit of building elements. Aware of this fact, most of building codes are now focused on strengthening the insulation of the building envelope [3] in order to achieve greater energy savings. Aware of this fact, most of the building codes for energy saving are focused on strengthening the insulation of the building envelope [4].

Within this legislative framework, the use of External Thermal Insulation Composite Systems (ETICS) has been increasing in the last decade. ETICS generally consist of placing insulation panels onto the external surface of a wall (support layer) and covering them with thin rendering layers. From the design point of view, ETICS may be differentiated according to the method of fixing the insulation onto the wall: purely bonded, bonded with supplementary mechanical fixings, mechanically fixed ETICS with supplementary adhesive and purely mechanically fixed ETICS. In the most common applications, the insulation layer is fixed using an adhesive mortar layer with supplementary mechanical fixings (anchors). The mechanical fixings are used primarily to provide stability until the adhesive has dried and act as a temporary connection to avoid the risk of detachment [5].

Plastic anchors for ETICS consist of an expansion element and a plastic expansion sleeve with a plate for fixing ETICS [6]These anchors the safety when compared to a purely bonded solution. However, they also presents higher thermal conductivity than the insulation product, which means that they act as thermal bridges and locally increase the heat transfer [7]. The manufacturers recommend a density of 5 to 8 anchors $/ \mathrm{m}^{2}$. Nevertheless, the number of fixation could be studied and could be higher in some cases, like on winding zones or high-rise buildings.

Reports on the occurrence of some anomalies associated with using ETICS can be in the literature review [8] [9]. Most known defects are related with an inadequate installation of the system. For example, badly prepared supporting layer [10] or insufficient anchoring of the insulation to the support layer [11]. Missing anchors aggravate the movement of insulation panels due thermal shrinkage/expansion phenomena [12] and contribute to the deterioration of the system, ultimately decreasing the lifetime of the façade [13]. Infrared Thermography (IRT) inspections could be applied to evaluate the presence of anchors and assess anomalies in the façade. Using this technique in ETICS may allow not only the evaluation of the extension of the underlying problem, but also the identification of its cause [14]. As IRT is a non-destructive and non-contact testing method [15], this technique is particularly useful in the predictive maintenance of buildings facades [16].

Most IRT inspections performed in buildings are done with its components under their normal conditions and following a passive approach [14]. Furthermore, there are several parameters which affect thermographic measurements, namely, emissivity, reflectivity, environmental conditions, colour and others [17]. The mains errors of thermographic analyses under real conditions are: incorrect evaluation of object emissivity, ambient and atmospheric temperatures, camera-to-object distance and/or humidity; and influence of ambient radiation (direct or reflected) arriving at the camera detector [18]. So, the reproducibility of results depends on many factors and some system characteristics or anomalies may not be identified during the inspection. An alternative to overcome those difficulties is to apply active IRT, which is a more reliable technique for qualitative and quantitative inspections. 
Active IRT uses an artificial heat source to induce higher temperature differences on the thermal images, making the detection of defects possible. With a use of a known stimulus, it's possible to characterize the defects found and perform a quantitative analysis [19]. There are several different active IRT techniques available, among which the most popular are pulse thermography and lock-in thermography [19] [20]. The pulse thermography consists in heating the specimen for a short time period (using laser or lamps) and recording its temperature decay. The lock-in thermography is based on sinusoidal stimulation (using flash lamps or thermal emitters). The surface temperature evolution is recorded and, via Fourier Transform, both the amplitude and phase of the thermal waves are obtained [14].

In this context, this paper aims to apply active thermography techniques (with different thermal stimulus procedures) to detect the existence and the location of plastic anchors in an ETICS installation. The heat sources used are halogen lamps, infrared lamps and air heaters. The measurements are performed in a laboratorial environment using different specimens (with different finishing coats) using the reflection mode approach. The results were processed using not only the time domain, but also the frequency domain, namely by means of a phase contrast method.

\section{Methodology}

An active infrared thermography analysis was performed using a phase contrast approach. A brief description of the testing specimens and the experimental apparatus is given in the following sections.

\subsection{Specimen description}

An ETICS application on a wooden substrate was used for testing. The specimen is composed by expanded cork agglomerate (ICB) fixed by adhesive mortar with auxiliary mechanical fixing (plastic anchors and metallic screws) and a reinforced base coat (single mesh and double mesh). In order to evaluate the effects of using different rendering systems, the test specimen contains two types of finishing coats. Additionally, for comparison purposed, an ETICS zone without any finishing coat has also been analysed. The specimens were built within a movable frame with a $2.8 \mathrm{~m} \times 2.8 \mathrm{~m}$ size. Figure 1 shows the test specimen with the two kinds of finishing coats (zone A and B) and the zone without any finishing coat (zone C).

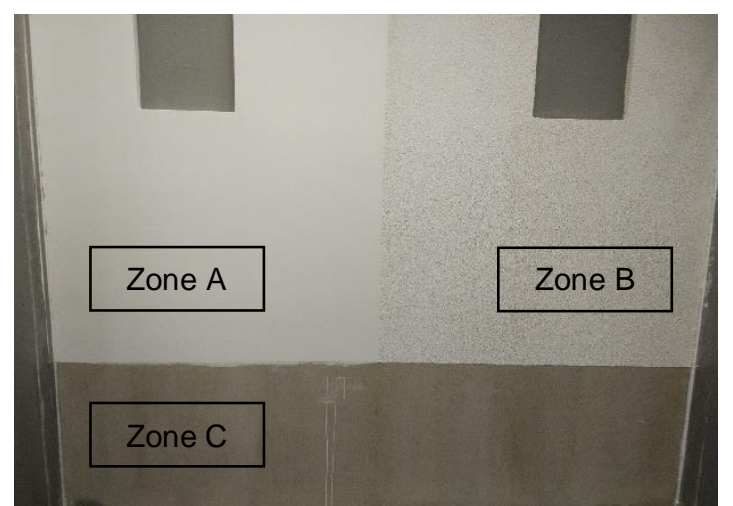

Figure 1: Test specimen: zone $A$ with smooth finishing, zone $B$ with rough (sandblasted) finishing and zone $C$ only with base coat.

\subsection{Test procedures}

The test procedures include measurements using unsteady thermal stimulus in reflection mode, meaning that the thermal energy is delivered to the surface from the same side in which data is being recorded. The stimulation of the specimen surface was triggered using different heat sources, namely an air heater, halogen lamps and infrared lamps. Initially, the reflected temperature was estimated, by placing a crumpled-up piece of aluminium foil on the surface and by measuring the average temperature of the foil target, with emissivity set to one. After adjusting the reflected temperature value, the thermal emissivity was measured. The measurements were performed for a set of conditions with changing heating and acquisition periods. The time period of the heating was either 120 seconds (tests with total duration of 512 seconds) or 400 seconds (longer tests with 2048 and 4096 seconds). The acquisition frequency was defined at $0.25 \mathrm{~Hz}$ (in the shorter tests), $0.32 \mathrm{~Hz}$ (in the medium length tests) and $0.0625 \mathrm{~Hz}$ (in the case of the longer tests). In order to assure laboratory conditions, the tests were performed inside a climatic chamber. Figure 2 shows the test apparatus. The tests were performed with the camera placed $0.70 \mathrm{~m}$ away from the surface of the specimen.

Active IRT tests were performed using a FLIR A615 camera connected to a control unit (Automation Technology IRX-Box) and to a computer with IR NDT 1.74 software. The IRT camera has the following technical specifications: $640 \times 480$ pixels resolution; $7.5-14 \mu \mathrm{m}$ spectral range; field of view (FOV) of $25^{\circ} \times 19^{\circ} ; 0.68 \mathrm{mrad}$ spatial resolution; thermal sensitivity/noise equivalent temperature difference (NETD) $<0.05{ }^{\circ} \mathrm{C} @ 30{ }^{\circ} \mathrm{C}$ and accuracy of $\pm 2{ }^{\circ} \mathrm{C}$ or $2 \%$. 


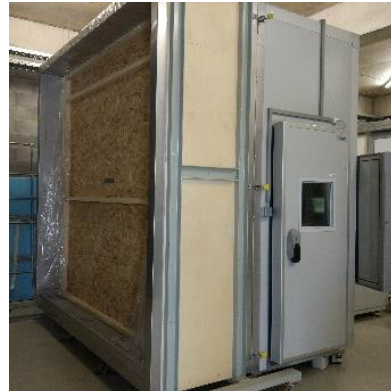

a)

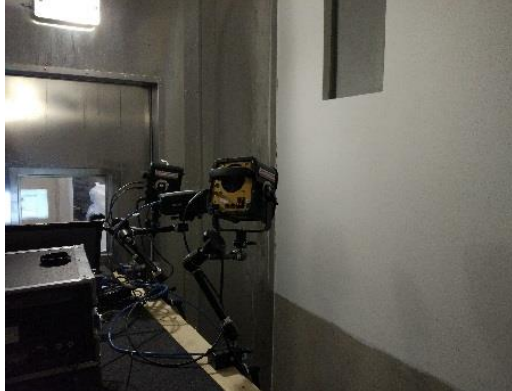

b)

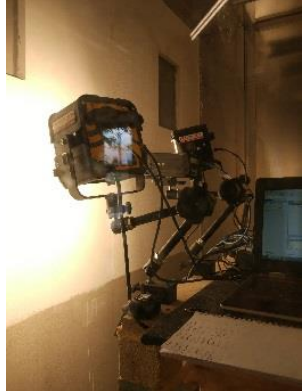

c)

Figure 2: Test apparatus: a) outside view of the chamber; b) inside view of the chamber; c) testing with halogen lamps.

The main objective of these tests is to evaluate the influence of the heating conditions when characterizing the mechanical fixing (by means of detecting the plastic anchors) in different ETICS test specimens.

\section{Results}

In this section, some of the results obtained in reflection modes with halogens lamps are presented. The analysis of the results was done following two distinct approaches: in time domain, by plotting two-dimensional temperature patterns, or in frequency domain, by generating phase contrast imaged two-dimensional phase contrast images and phase contrast curves for specific receivers. Results in the frequency domain were calculated by applying a Fourier transform to the time domain temperature pattern results. Phase contrast was computed by calculating the difference between the thermal wave phase amplitude for each point of the grid of pixels (receiver) and the phase recorded at a receiver placed outside the area of influence of the anchors/defects which is not affected by the thermal heterogeneity of those singularities (sound zone). The resulting phase contrast curves for a certain receiver shows the difference between the phase result recorded at that specific pixel and at a pixel somewhere in the sound zone, for the full range of frequencies. Table 1 shows some examples of IRT results obtained using two halogen lamps $(2500 \mathrm{~W})$ in the zone A. The phase contrast curves were obtained by considering two receivers on the defect (dark blue curves) and one receiver at the sound area (light blue curve)

Table 1: IRT results obtained using halogen lamps - zone A.

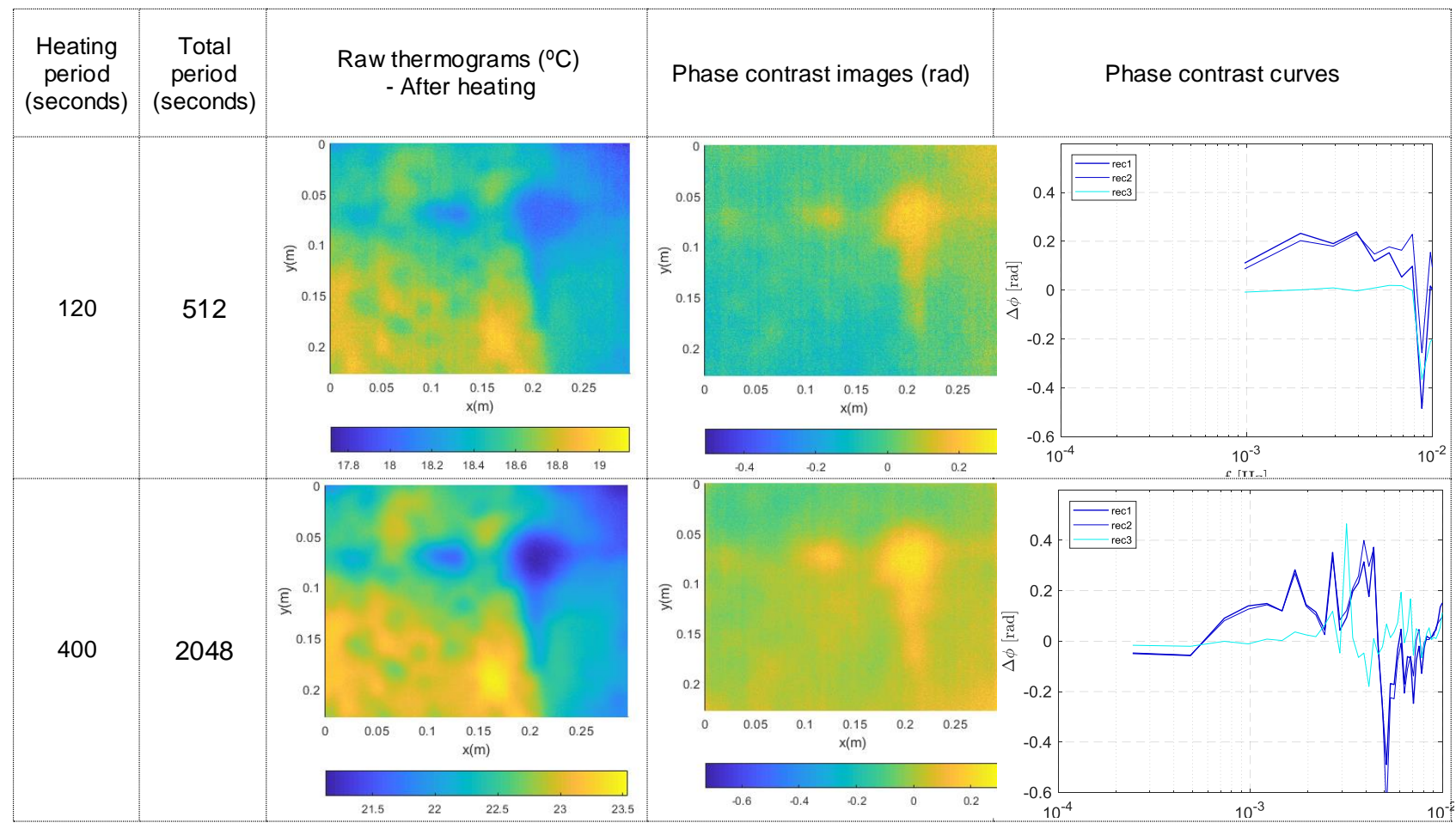




\section{Final Remarks}

An experimental campaign was performed using active thermography techniques to evaluate the presence of anchors in external thermal insulation composite systems. The main goal of this work was evaluate the influence of the heating period and heating system in the detection of plastic anchors in different ETICS renderings.

IRT is a non-invasive technique that allows the detection of sub surfaces elements. Its use for detecting anchors was explored in this paper, using different heating mechanisms and data processing techniques. This study demonstrates the ability of using IRT technology to confirm that anchors were adequately used and to identify their placement. This is particularly important since the anchors increase the level of suction strength of the insulation fixing, which is crucial to prevent detachment of the system from the facade. The reflection mode was performed using halogen lamps, infrared lamps and an air heater. The results were analysed in time domain (temperature pattern images) and in the frequency domain (in terms of phase contrast images).

It is concluded that when using halogen lamps, longer heating periods (400 seconds) lead to better results. The results also demonstrate the advantages of using phase contrast phases when detecting anchors and/or defects.

\section{Acknowledgements}

This work was developed under the project POCI-01-0247-FEDER-003179 - "REVI CLEAN FACADE", approved through the Incentive Scheme R\&TD Co-promotion Projects and co-funded by the European Regional Development Fund through Compete2020. This work has also been supported by the doctoral FCT grant PD/BD/135194/2017.

\section{REFERENCES}

[1] European Parliament. Directive 2010/31/EU of the European Parliament and the Council of 19 May 2010 on the energy performance of buildings. In: Official Journal of the European Union vol. L 486, pp. 13-35, 2010.

[2] European Parliament. Directive 2012/27/EU of the European Parliament and the Council of 25 October 2012 on the energy efficiency. In: Official Journal of the European Union, pp. 1-56, 2012.

[3] R. Garay, B. Arregi, and P. Elguezabal. Experimental Thermal Performance Assessment of a Prefabricated External Insulation System for Building Retrofitting. In: Procedia Environ. Sci., vol. 38, pp. 155-161, 2017.

[4] J. Lee, J. Kim, D. Song, J. Kim, and C. Jang. Impact of external insulation and internal thermal density upon energy consumption of buildings in a temperate climate with four distinct seasons. In: Renew. Sustain. Energy Rev., vol. 75, pp. 1081-1088, 2017.

[5] Organisation for Technical Approvals. ETAG 004 - Guideline for European technical approval of external thermal insulation composite systems with rendering. European, Brussels, Belgium, 2000 (Amended February 2013).

[6] European Assessment Document - EAD 330196-01-0604: Plastic anchors made of virgin or non-virgin material for fixing of External Thermal Insulation Composite Systems, EOTA, July 2017.

[7] R. Ji, Z. Zhang, Y. He, J. Liu and S. Qu. Simulating the effects of anchors on the thermal performance of building insulation systems. In: Energy and Building, vol. 140, pp. 501-507, 2017.

[8] J. Mendes da Silva and J. Falorca. A model plan for buildings maintenance with application in the performance analysis of a composite facade cover. In: Construction and Building Materials, vol. 23, no. 10, pp-1718-1729, 2010 .

[9] T. Lima. Fenómenos de pré-patologia em manutenção de edifícios aplicação ao revetimento ETICS. Masters dissertation, Faculty of Engineering of the University of Porto, 2005.

[10] I. Flores-Colen and J. de Brito. A systematic approach for maintenance budgeting of buildings faades based on predictive and preventive strategies. In: Construction and Buildings Materials, vol. 24, no. 9, pp. 1718-1729, 2010.

[11] B. Amaro, D. Saraiva, J. de Brito, and I. Flores-Colen. Inspection and diagnosis system of ETICS on walls. In: Construction and Buildings Materials, vol. 47, pp. 1257-1267, 2013.

[12] V. Sulakatko, I. Lill, and E. Liisma. Analysis of On-site Construction Processes for Effective External Thermal Insulation Composite System (ETICS) Installation. In Procedia Economics and Finance, vol. 21, pp. 297-305, 2015.

[13] V. Sulakatko, I. Lill, and E. Witt. Methodological Framework to Assess the Significance of External Thermal Insulation Composite System (ETICS) on-site Activities. In: Energy Procedia, vol. 96, pp. 446-454, 2016.

[14] N. Simões, I. Simões, C. Serra and A. Tadeu. Thermographic inspection of external thermal insulation systems with mechanical fixing. In: SPIE Sensing Technology + Applications Conference, 2015

[15] T. Lourenço, L. Matias and P. Faria. Anomalies detection in adhesive wall tiling systems by infrared thermography. Construction and Buildings Materials, vol. 148, pp. 419-428, 2017.

[16] C. Balaras and A. Argiriou. Infrared thermography for building diagnostics. In: Energy and Buildings, vol. 34, pp. 171-183, 2002.

[17] E. Barreira and V. Freitas. Evaluation of building materials using infrared thermography. In:Construction and Buildings Materials, vol. 21, no. 1, pp. 218-224, 2007

[18] E. Edis, I. Flores-Colen and J. de Brito. Passive thermographic detection of moisture problems in façades with adhered ceramic cladding. In: Construction and Buildings Materials, vol. 51, pp. 187-197, 2014. 
[19] C. Serra, A. Tadeu and N. Simões. Heat transfer modeling using analytical solutions for infrared thermography applications in multilayered buildings systems. In: International Journal of Heat and Mass Transfer, vol. 115, pp. 471-478, 2017.

[20] F. Lopez, C. Ibarra-Castanedo, V. Nicolau and X. Maldague. Optimization of pulsed thermography inspection by partial least-squares regression. In: NDT\&E International, vol. 66, pp. 128-138, 2014. 